\title{
Microstructure and Properties of an Al 6061/Galvanized Plate Fabricated by CM'T Welding
}

\author{
ZHAVG Qi $^{1,2}$, ZHANG Peilei ${ }^{1,2,3^{*}}$, YU Zhishui ${ }^{1,2^{*}}$, YAN Hua ${ }^{1,2}$, SHI Haichuan ${ }^{1,2}$, \\ WU Di ${ }^{1,2}$, LI Shaowei ${ }^{1,2}$, TIAN Yingtao ${ }^{4}$
}

(1. School of Materials Engineering, Shanghai University of Engineering Science, Shanghai 201620, China; 2. Shanghai Collaborative Innovation Center of Laser Advanced Manufacturing Technology, Shanghai 201620, China; 3. Fraunhofer Institute for Laser Technology ILT, Aachen 52074, Germany; 4. Department of Engineering, Lancaster University, Lancaster, UK)

\begin{abstract}
Aluminum alloy 6061 was welded with zinc coated low carbon steel by cold metal transfer (CMT). The microstructure composition, morphology and growth process of the welding joint and the HAZ were researched. The weld area on the side of the galvanized steel sheet mainly contains $\mathrm{Fe}_{2} \mathrm{Al}_{5}$. And on the side of the aluminum alloy substrate, it is mainly filled with a needle-like $\mathrm{FeAl}_{3}$. At the same time, $\mathrm{Al}_{8} \mathrm{Fe}_{2} \mathrm{Si}$ is formed at the edge of $\mathrm{FeAl}_{3}$. The zinc-rich region on the side of the aluminum alloy mainly contains an aluminum-zinc solid solution and an aluminum-zinc co-crystal, and the current size had no significant effect on the type and morphology of the compounds produced in the interface layer.
\end{abstract}

Key words: cold metal transfer, microstructure; microhardness; dissimilar metals

\section{Introduction}

In recent years, the direction of the developing lightweight vehicles, environmental protection, energy saving and safety has become the goal pursued by the automotive industry ${ }^{[1]}$. A large number of aluminum alloy used in the car manufacturing process, reduced the total mass of car, while reducing fuel consumption in the car driving process. And aluminum parts recycling can also promote material savings. However, due to safety considerations, the all-aluminum body has not been promoted ${ }^{[2-6]}$. Therefore, the increasing use of different materials "steel + aluminum" in the automotive field has become the development direction of the automobile body. In many industrial sectors, sheet steel is the more basic material, and galvanized

ZHANG Qi (张琪): E-mail: q985926169@163.com

*Corresponding author: ZHANG Peilei (张培磊): Assoc. Prof;; Ph D; E-mail: peilei@sues.edu.cn; YU Zhishui (于治水): Prof.; Ph D; E-mail: yu_zhishui@163.com

Funded by National Natural Science Foundation of China (No. 51905333), Shanghai Sailing Program (No. 19YF1418100), Shanghai Science and Technology Committee Innovation Grant (Nos. 17JC1400600, 17JC1400601, 19511106400 and 19511106402), Shanghai Local Colleges and Universities Capacity Building Special Plan Project (No. 19030501300) steel is widely used in the automotive industry due to its excellent corrosion resistance. Therefore, it becomes particularly crucial to achieve an effective and reliable connection of the aluminum alloy and the galvanized steel sheet.

During the welding process, owing to the excessive evaporation of the low-melting-point zinc, it has a serious influence on the macroscopic appearance and quality of the welded joint. On the other hand, there is a big difference between aluminum and steel in the thermal physical properties. Therefore the cracks can be found in the join easily, owing to the existence of residual stress. Find a reasonable solution to solve the aluminum alloy and steel welding problems in the welding process is particularly important ${ }^{[7]}$.

In order to solve the aluminum alloy and welding process problems, CMT welding technology invented by Fronius can effectively solve the problems in the welding of aluminum and galvanized steel. Cold metal transfer (CMT) is a modified gas metal transfer welding (GMAW) process where the filler wire is intentionally retracted instantaneously after the occurrence of the short circuit. And welding process control, wire to give and walking can be directly combined. The process of wire walking affects the control of the welding process, and the welds process also controls the wire walking. The two interact with each other to form a system. The droplet transits to the melt pool in a short-circuit 
transits, and the current almost becomes zero when the droplet falls off.

The traditional short-circuit transition has a larger welding current, and droplet transfer is not smooth and easy to lead to splashing. Owing to the small current during the droplet transfer, the CMT arc combustion transition is stable. The welded joint does not need to be processed after welding, which makes the CMT have a certain advantages compared with the traditional arc welding and brazing ${ }^{[8-11]}$.

R Vranakova et al successfully achieved the welding of $0.9,1.5 \mathrm{~mm}$ thick galvanized steel and $1.1,1.5 \mathrm{~mm}$ thick aluminum-magnesium alloy by MIG arc welding, and the filler material was $\mathrm{AlSi}_{5}$ wire $^{[8]}$. The experimental results show that the interface intermetallic compound thickness is small. Cracks occurred mainly in the heat affected zone of the aluminum alloy based metal, and the joint tensile strength is high. Due to the arc force and the plasma flow, zinc-rich zone is formed at the brazing feet.

In this study, CMT was used to weld aluminum 6061 to zinc coated low carbon steel. In addition, optical micrograph, scanning electron microscope (SEM), X-ray diffraction (XRD) and energy dispersive spectrometer (EDS) were used to analyze the weld microstructure.

\section{Experimental}

The selected materials were $2 \mathrm{~mm}$ thick aluminum alloy 6061 and $2 \mathrm{~mm}$ thick zinc coated steel (Q235). $\mathrm{AlSi}_{5} 1.2 \mathrm{~mm}$ was selected as a filler wire material and the overlap length between the steel and aluminum alloy was $15 \mathrm{~mm}$ (Fig.1). CMT Fronius$5000 \mathrm{i}$ equipment model were used in this study. Argon gas was used as the shielding gas. The basic parameters of CMT welding can be seen in Table 1. The welding parameters can be seen in Table 2. The angle of CMT arc torch was set at $60^{\circ}$ and welding torch was aligned on aluminum side. Before welding, sandpaper was used to remove the aluminum surface oxide film, then cleaned with acetone, and ultrasonic cleaning. After the test was completed, the cross section was taken. (corrosion of the aluminum alloy side with $5 \%$ hydrofluoric acid solution, corrosion of the galvanized steel side with $4 \%$ nitric acid alcohol). The microstructure was observed under a VHX-600K microscope. The tensile properties of lap joints were tested through AG-25TA electronic universal testing machine. Hitachi S3400 scanning electron microscope was used. Using HXD-1000TMSC

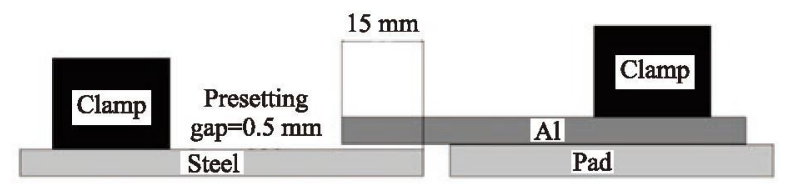

Fig.1 Schematic of the welding process

Table 1 The basic parameters of CMT welding

\begin{tabular}{ccccc}
\hline $\begin{array}{c}\text { Nozzle } \\
\text { tip/mm }\end{array}$ & $\begin{array}{c}\text { Wire } \\
\text { extension } \\
/ \mathrm{mm}\end{array}$ & $\begin{array}{c}\text { Protect } \\
\text { gas flow } \\
/(\mathrm{L} / \mathrm{min})\end{array}$ & $\begin{array}{c}\text { Pre- } \\
\text { ventilation } \\
\text { time } / \mathrm{s}\end{array}$ & $\begin{array}{c}\text { Continuous } \\
\text { ventilation } \\
\text { time } / \mathrm{s}\end{array}$ \\
\hline 13 & 12 & 15 & 3 & 3 \\
\hline
\end{tabular}

Table 2 The welding parameters at different welding speed

\begin{tabular}{cccc}
\hline Current/A & $\begin{array}{c}\text { Voltage } \\
/ \mathrm{V}\end{array}$ & $\begin{array}{c}\text { Welding speed } \\
/(\mathrm{mm} / \mathrm{min})\end{array}$ & $\begin{array}{c}\text { Wire feed speed } \\
/(\mathrm{m} / \mathrm{min})\end{array}$ \\
\hline 70 & 12.7 & 350 & 3.9 \\
\hline
\end{tabular}

/ LCD Vickers microhardness tester to test the hardness of the connector (the load was set at $200 \mathrm{gf}$ and held for about 15 seconds).

\section{Results and discussion}

\subsection{Joint microstructure analysis}

The melting point of aluminum alloy is much lower than that of galvanized steel. Therefore, during the welding process, most of the heat of the arc acts on the aluminum alloy. Under the arc heat aluminum alloy was melted, and the other side of the galvanized steel was only micro-melting or not melting. For aluminum alloy it was fusion welding, but for galvanized steel it was a brazing process.

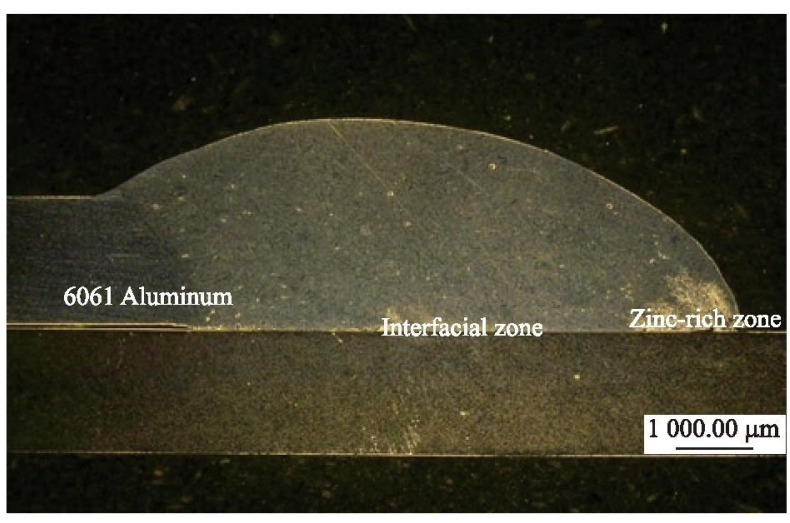

Fig.2 Cross-section image of the weld joint

The cross section macro appearance of welding joints was shown on the Fig.2. And it was divided into several areas (the melting zone and heat affected zone which near the side of the base metal of aluminum alloy, the interface reaction zone of aluminum alloy and galvanized steel). During cooling the melting zone was formed by the base metal aluminum alloy and melting 
wires diffusion and dissolution. The zinc-rich zone was formed because the remaining zinc was pushed to the weld toe by the arc force. Different phase was formed on each part of welding joints, which results in a different nature.

3.1.1 Microstructure analysis of base metal melting zone and HAZ

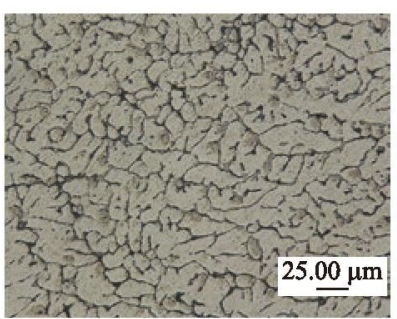

(a) Upper melting zone Fig.3 Microstructure of melting zone of aluminum meta

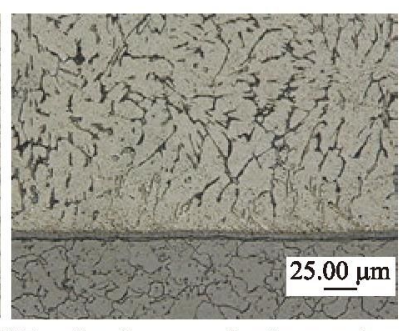

(b) Interface between aluminum and steel

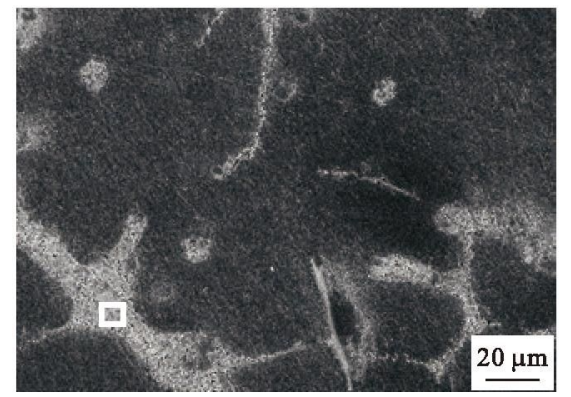

Fig.4 Microstructure of Al-Si eutectic of melting zone

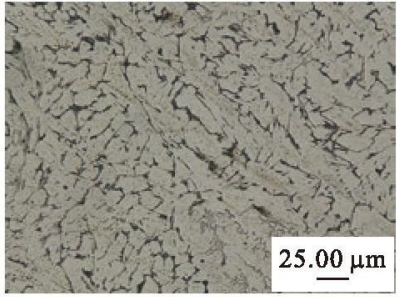

(a) Remote heat affected zone

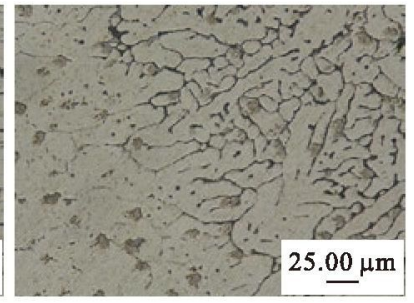

(b) Near heat affected zone
Fig.5 Microstructure of heat affect zone

tures of aluminum alloy and galvanized steel are different. Fig. 5 shows different microscopic morphologies in different ares. The reason is that the thermal cycle is different in the area close to the arc and the area far from the arc, resulting in different phases. In the heat-affected zone of aluminum, since the strengthening phase has a lower melting point, it is less affected by arc heat. The original structure of the material is rod-shaped crystal grains, which then melt as the arc slowly heats up. As the heat decreases, the liquid crystallizes to form a massive substance. If the crystal grains in the center area have a large heat input, it is easy to cause excessive growth of the crystal grains. The brittleness of welded joints increases,

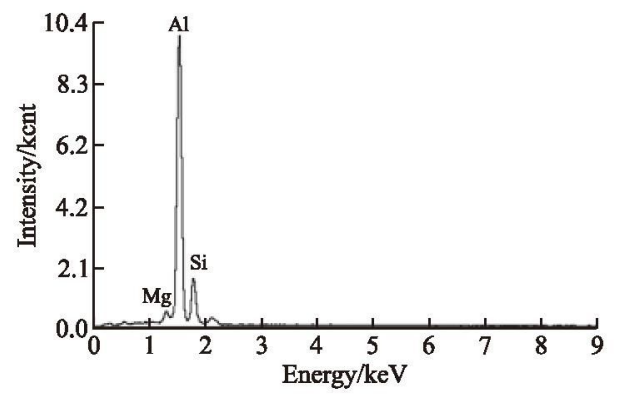

The microstructure of base metal melting zone can be seen in Fig.3. At the top of the melting zone which is far from the center of the heat source, with a larger cooling rate equiaxed crystal was formed which was shown in Fig.3 (a). And the $\alpha-\mathrm{Al}$ and $\mathrm{Al}-\mathrm{Si}$ eutectic phases dissolved and different elements diffuse each other. At the low cooling rate, the grains near the galvanized steel had enough time to grow up. A columnar $\alpha-\mathrm{Al}$ and $\mathrm{Al}-\mathrm{Si}$ eutectic structure was formed which could be seen from Fig.3 (b).

Fig. 4 shows the scanning electron microscopic image of melting zone. The white grain boundary region is composed of $\mathrm{Ai}-\mathrm{Si}$ eutectic grains. It contained $\mathrm{Mg}, \mathrm{Al}, \mathrm{Si}$ elements, and the relative atomic number ratio of $\mathrm{Al}$ and $\mathrm{Si}$ is 73.16: 23.90.

Due to the influence of arc heat, the microstruc-

which seriously affects the quality of joints. Therefore, it is important to control the heat input to obtain good welded joint quality.

3.1.2 Microstructure analysis of the interface

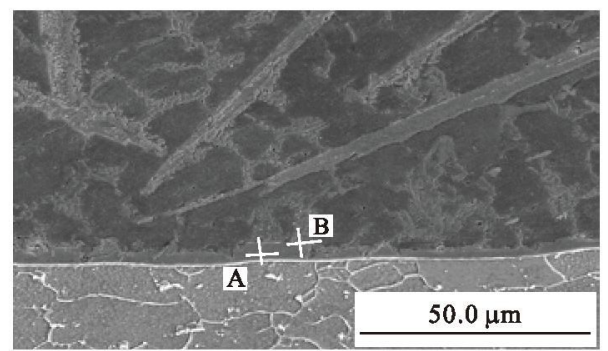

Fig.6 Microstructure of the interfacial reacting zone

Table 3 Compositions of positions in Fig.6/at\%

\begin{tabular}{ccccc}
\hline Point & $\mathrm{Si}$ & $\mathrm{Fe}$ & $\mathrm{Al}$ & $\mathrm{Zn}$ \\
\hline $\mathrm{A}$ & 4.17 & 26.70 & 68.29 & 0.85 \\
$\mathrm{~B}$ & 2.50 & 26.22 & 71.05 & 0.24 \\
\hline
\end{tabular}

Fig. 6 shows the microstructure of interface. Under the arc heat liquid solder was diffused to galvanized steel, and liquid zinc-plated steel also diffused into the solder. A certain thickness of intermetallic compounds 
were generated. As the current was small, the interface compound had a little growth and became a small acicular grain. And with the arc heat input change, the grain growth patterns also changed. Near the side from the galvanized sheet, compound was grown as tongue or strip shape, and spread along the inside of galvanized steel.

In order to quantify the chemical composition of intermetallic compounds, EDS was performed at two points $\mathrm{A}$ and $\mathrm{B}$. The test results showed that the compounds mainly contained $\mathrm{Fe}$ and $\mathrm{Al}$ alloying elements. Compound atomic fraction ratio was $\mathrm{Fe} /$ $\mathrm{Al} \approx 2.5$ in the side of galvanized steel. Therefore, it can be judged as $\mathrm{Fe}_{2} \mathrm{Al}_{5}$ phase. For $\mathrm{Fe}-\mathrm{Al}$ intermetallic compound, $\mathrm{Fe} / \mathrm{Al} \approx 0.33 \approx 1 / 3$, and it was known as $\mathrm{FeAl}_{3}$ phase. The ratio of the atomic fraction of the whisker compound was $\mathrm{Fe} / \mathrm{Al} \approx 0.37$, and it can be judged as a mixture of $\mathrm{Fe}_{2} \mathrm{Al}_{5}$ and $\mathrm{FeAl}_{3}$.

In order to analyze specific composition of the compound more precisely, the joints was analyzed by XRD. The test results can be seen in Fig.7.

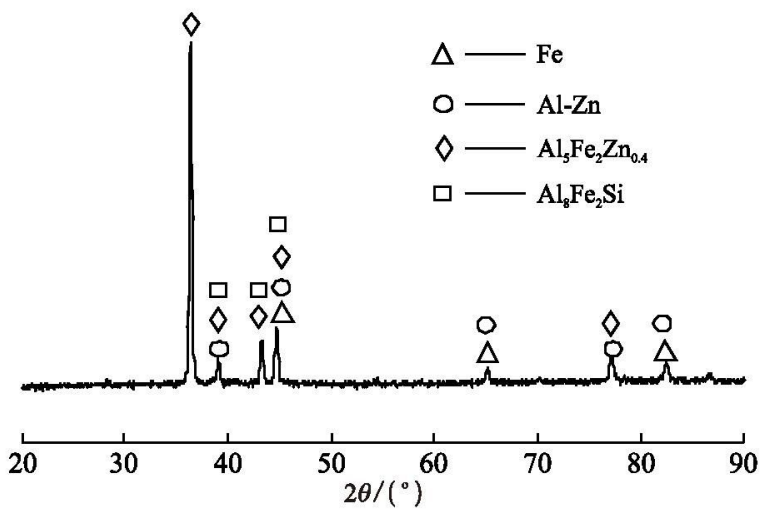

Fig. 7 XRD patterns of interface by aluminum/steel welding

The phase which was generated in the interface includes $\mathrm{Al}_{5} \mathrm{Fe}_{2} \mathrm{Zn}_{0.4}, \mathrm{Al}_{8} \mathrm{Fe}_{2} \mathrm{Si}$ and $\mathrm{Al}-\mathrm{Zn}$ eutectic. The $\mathrm{Al}_{5} \mathrm{Fe}_{2} \mathrm{Zn}_{0.4}$ phase has good ductility and its presence can alleviate the problems caused by the brittle phase of the joint. There were some $\mathrm{Al}_{8} \mathrm{Fe}_{2} \mathrm{Si}$ generated around $\mathrm{FeAl}_{3}$ phase. Because $\mathrm{Al}_{8} \mathrm{Fe}_{2} \mathrm{Si}$ had a smaller microhardness, the brittleness can be decreased. The zinc-rich zone was formed at the weld toe, composed of the Al-Zn eutectic and Al-Zn solid solution. The dissolution of zinc obstructed the grain deformation and increased the hardness of the phase, owing to the pinning effect.

Affected by the arc heating range, in the area closed to the base metal galvanized steel, there was less heat input. Therefore, the elements failed to fully diffuse into each other, and formed $\mathrm{Fe}_{2} \mathrm{Al}_{5}$ with less aluminum. And it grows as a whisker on the side close to the solder. And as the reaction proceeded, the whisker-like compound near the solder changes its shape to waves. The grains will had a great grown and the $\mathrm{FeAl}_{3}$ phase was formed finally, due to the enrichment of aluminum and the great heat input. As the welding current increased, the arc heating area increased, and arc force, plasma flow and electromagnetic force also increased. Therefore, the agitation of liquid metal was enhanced and the whisker compound was shredded with agitation.
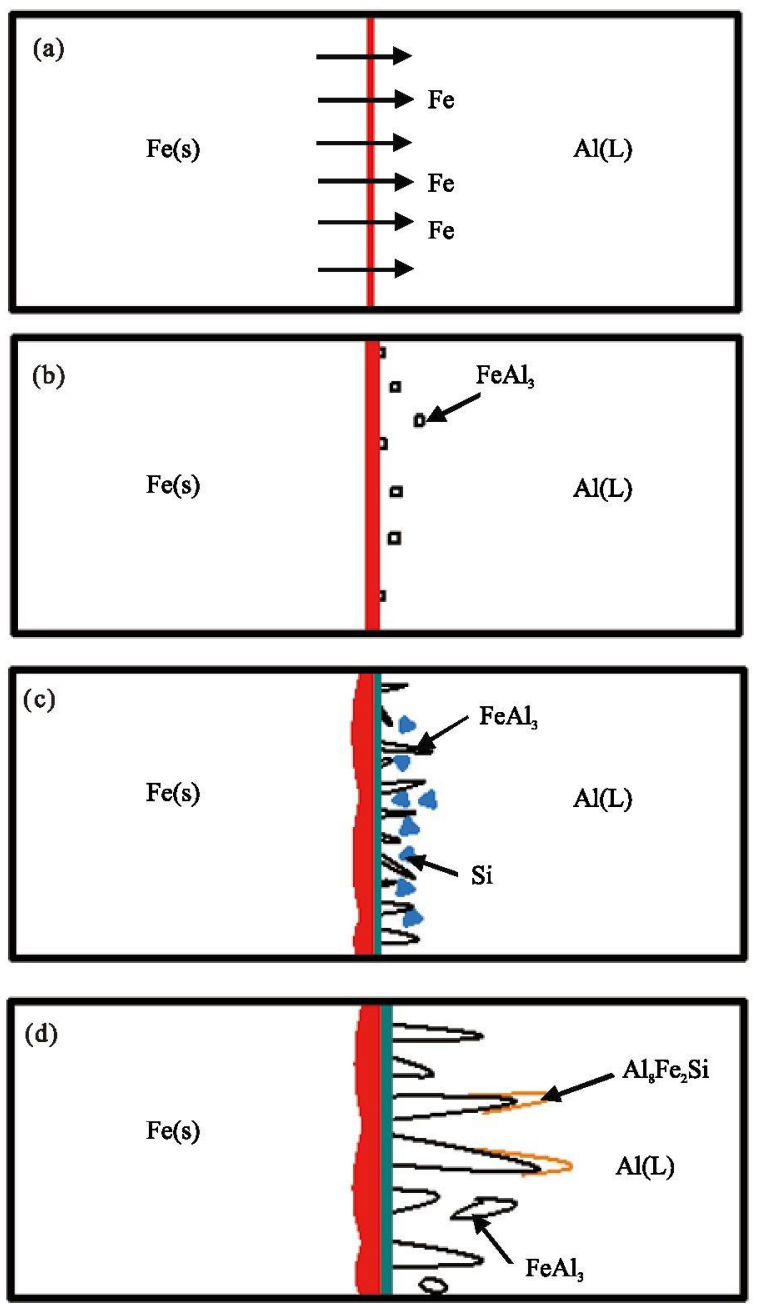

Fig.8 Growth model schematic of AlFeSi ternary alloy

With small heat input, the compound $\mathrm{Fe}_{2} \mathrm{Al}_{5}$ growth depended on the interface of solder joint. Smaller whisker-like intermetallics were shredded by the action of the arc agitation force and the longitudinal and lateral flow in the liquid solder. As the heat input increased, the are force, plasma flow force and electromagnetic force were further increased. Arcing agitation was more intense, and whiskerlike intermetallic compound $\mathrm{FeAl}_{3}$ was constantly fragmented into the brazing seam with the liquid metal 
together.

Fig. 8 shows the growth model schematic diagram of the intermetallics. With the arc force, the outer electrons of $\mathrm{Fe}$ atoms were excited atoms by heat and interacted with the $\mathrm{Al}$ atoms to diffuse (Fig. 8 (a)). Owing to the Si atoms, which promoted the dissolution of aluminum in iron, the reaction was more adequate. But, temperature influenced on this dissolution. Fig. 8 (b) and (c) show the growth model of the intermetallic compound $\mathrm{FeAl}_{3}$. Owing to the unevenness of arc heating, there is a difference in grain diffusion growth. Some of the excess $\mathrm{Si}$ atoms are precipitated by the dendrites and grow around them, causing crystal segregation. Fig.8(d) shows the intermetallic compounds further grow toward the center of the solder. Due to the Si atoms AlFeSi ternary alloy phase was generated and grew up around $\mathrm{FeAl}_{3}$. When growing to a sufficient extent, it is pushed into the brazed joint by the action of the arc force.

\subsubsection{Microstructure analysis of zinc-rich zone}

At the edge of arc heating, owing to the low temperature, some zinc elements were not completely volatilized. Under the action of are force, the zinc which was not completely volatilized was pushed out to the corner of the solder. The results of the energy spectrum analysis show that the edges of the weld mainly contain aluminum and zinc alloy elements. And it can be seen in Table 3. The heat source was in the form of Gaussian heat, and in the source edge the heat input was small. Therefore, Fe and Si mainly remained in the center of the interface zone to form intermetallic compounds. The zinc, which was not completely volatilized, flowed along with the brazing material to the brazing feet.

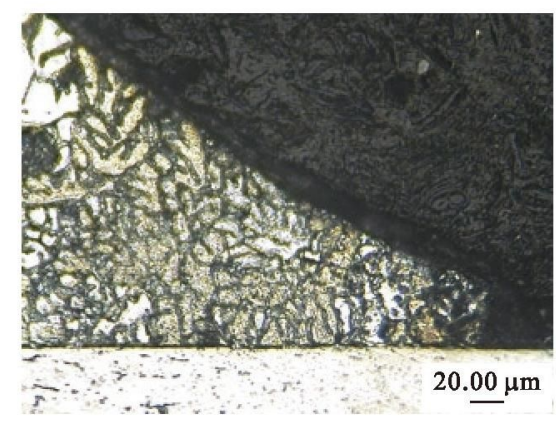

Fig. 9 The microstructure image of Zinc-rich zone

At the zinc-rich region on the edge of the solder, the thickness of the compound layer was gradually decreases due to insufficient energy. And it can be seen in Fig.9. The reason was that the reactions of $\mathrm{Fe}$ and $\mathrm{Al}$ was insufficient. On the other hand, the presence of zinc not only reduces the activity of iron atoms but also reacts with aluminum.

Fig.10 shows the microstructure of zinc-rich zone. Fig. 11 and Table 4 shows the EDS analysis of zincrich zone, and the compounds mainly contained $\mathrm{Al}$ and $\mathrm{Zn}$ elements. Combined with phase diagram, dendrites could be judged as aluminum-zinc $\alpha$ solid solution. Between the dendrite mass of aluminum-zinc eutectoid, bright white aluminum-zinc eutectic area was formed.
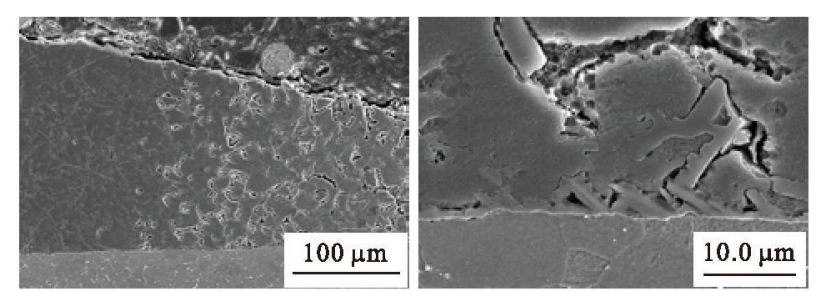

Fig.10 The microstructure of Zinc-rich zone

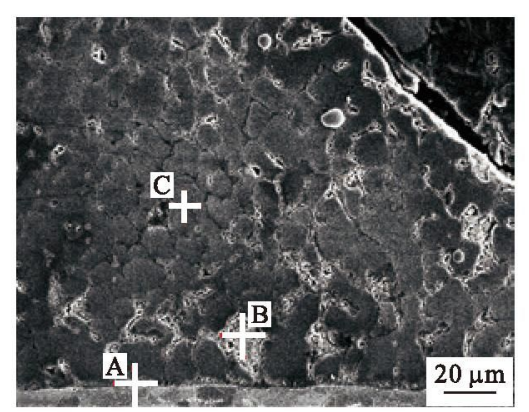

Fig.11 The EDS analysis of Zinc-rich region

Table 4 Compositions of positions in Fig.11/at\%

\begin{tabular}{cccc}
\hline Point & Fe & Al & Zn \\
\hline A & 12.89 & 85.33 & 0.78 \\
B & 7.47 & 91.65 & 0.88 \\
C & 0.76 & 82.36 & 16.88 \\
\hline
\end{tabular}

The growth model schematic of $\mathrm{Fe}_{2} \mathrm{Al}_{5} \mathrm{Zn}_{0.4}$ can be seen in Fig.12. Under arc heat, the zinc coating was dissolved and volatilized. And a part of the zinc coating was squeezed to the soldering feet to form a zinc-rich zone, as shown in Fig.12 (a) and (b). Due to the higher growth kinetics, $\mathrm{Fe}_{2} \mathrm{Al}_{5}$ grew faster than $\mathrm{FeAl}_{3}$. When the growth proceeded to a certain stage, the content of $\mathrm{Al}$ atoms increased and the $\mathrm{FeAl}_{3}$ phase was formed, as shown in Fig. 12 (c). In the zinc-rich part, $\mathrm{Zn}$ atoms diffused into the Al-Fe gap, and formed $\mathrm{Fe}_{2} \mathrm{Al}_{5} \mathrm{Zn}_{0.4}$ ternary compounds, as shown in Fig. 12 (d).

3.1.4 The microstructure defect analysis of joints

Fig. 13 shows the microstructure defect analysis of joints. Few pores existed in the joints, and were mainly distributed in the upper part of the melting zone of the aluminum alloy.

Owing to the surface oxide film and oil pollution and other pollutants, the stomata were formed. Low- 

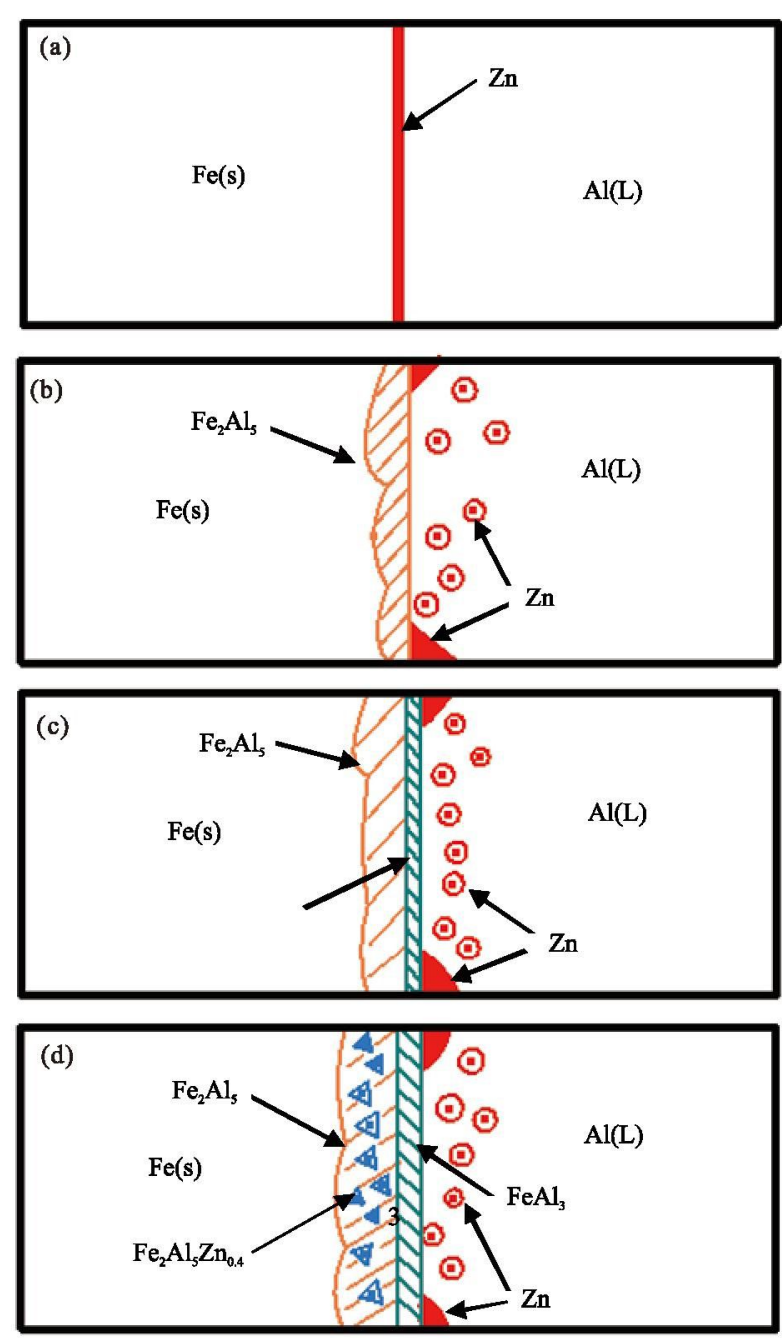

Fig.12 Growth model schematic of AlFeZn ternary alloy

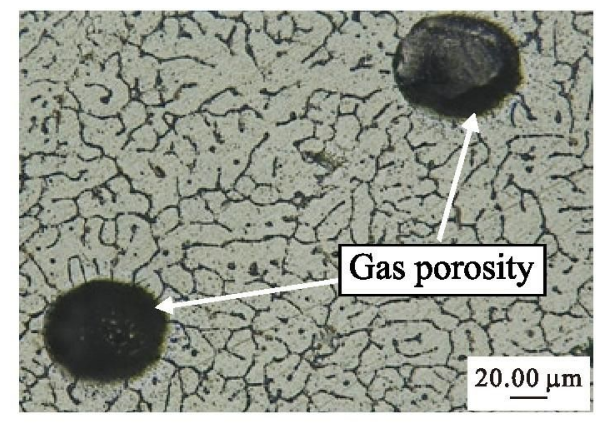

Fig. 13 Gas porosity in weld joint

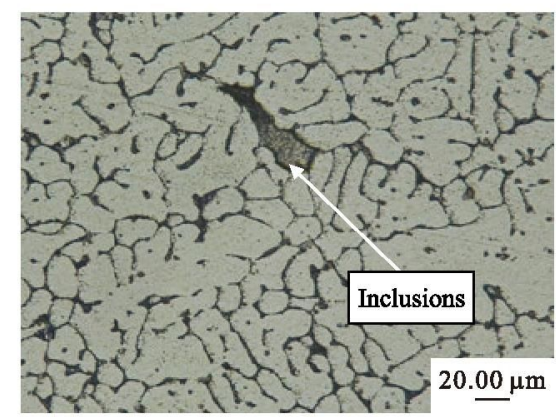

Fig.14 Inclusions in weld joint melting zinc was evaporated by the arc. The gas did not overflown when it was cooled and formed pores.

In the melting zone, there was a certain amount of black cluster inclusions. And it can be seen in Fig.14. The main reason was that aluminum surface did not clean up before welding test. Therefore, it was important to clean the base metal before welding.

\subsection{Mechanical properties of welded joints}

\subsubsection{Microhardness of welded joints}

The microhardness of the joint also reflected the quality of the joint. Therefore, it is important to research the microhardness of different welding joints zone. Fig. 15 shows the hardness line chart of zincrich. When closer to the toe, the microhardness had a gradually increase. Because of the Al-Zn solid solution strengthening phase and $\mathrm{Fe}_{2} \mathrm{Al}_{5} \mathrm{Zn}_{0.4}$ ternary alloy phase, the joint plasticity was increased and the tendency to brittleness was reduced. The more it closer to the weld toe site, the more solid solution strengthening phase there was, so its microhardness also increased.
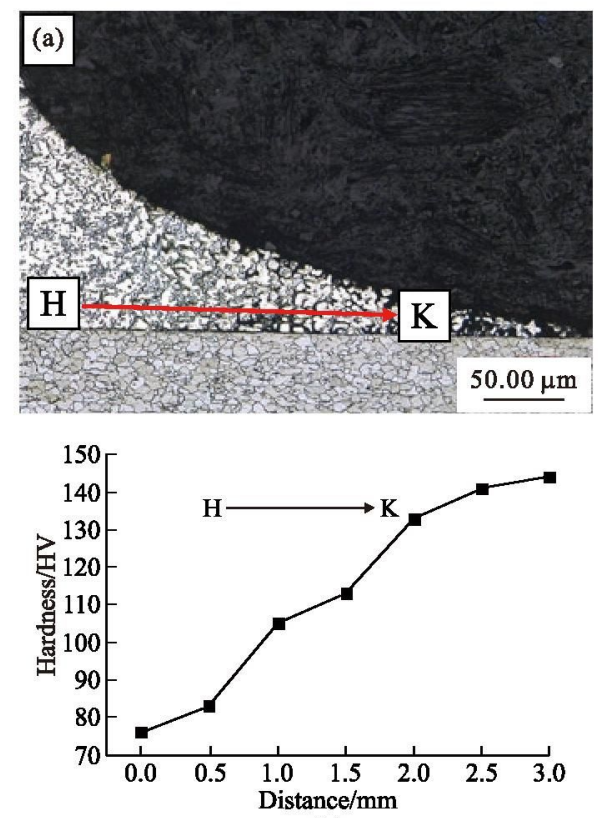

(b)

Fig.15 Distribution of Vickers hardness at zinc-rich region

The hardness became higher when the position was close to the interface between the brazing seam and the base metal. And the hardness of the interface was higher than that of the base metal and the brazed weld. The hardness of the side of the brazing seam was lower than the interface. That was because the $\mathrm{Al}$ diffused to the interface and reacted with $\mathrm{Fe}$, forming iron-aluminum compound particles at the interface. And the compound particles was diffusion distribution in the brazing seam, strengthening the brazing joints 
and brazing seam. Near the side of $\mathrm{Fe}$, the $\mathrm{Si}$ atoms were dissolved in $\mathrm{Fe}$ and the $\mathrm{Fe}$ atoms underwent lattice deformation. This was the basic principle of solid solution strengthening.
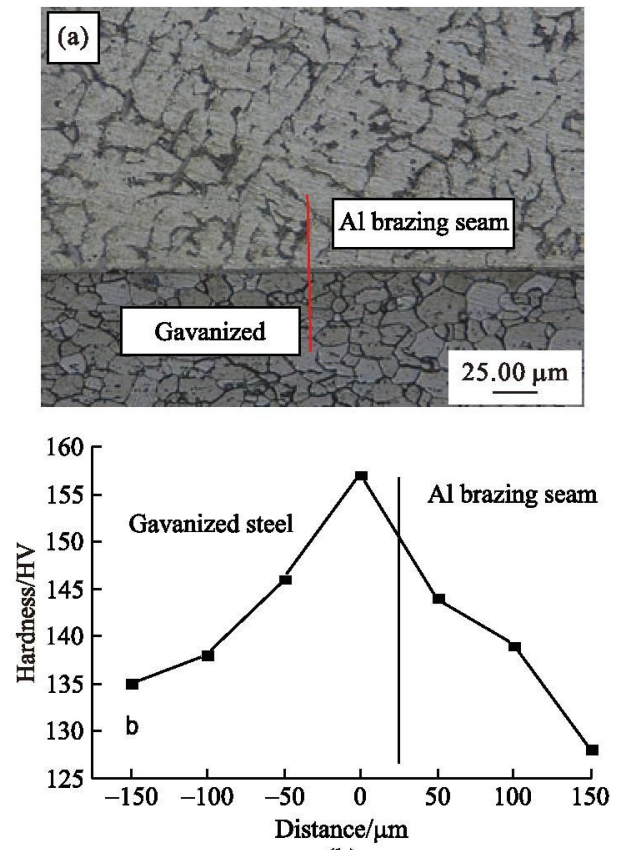

(b)

Fig.16 Distribution of Vickers hardness at interfacial zone
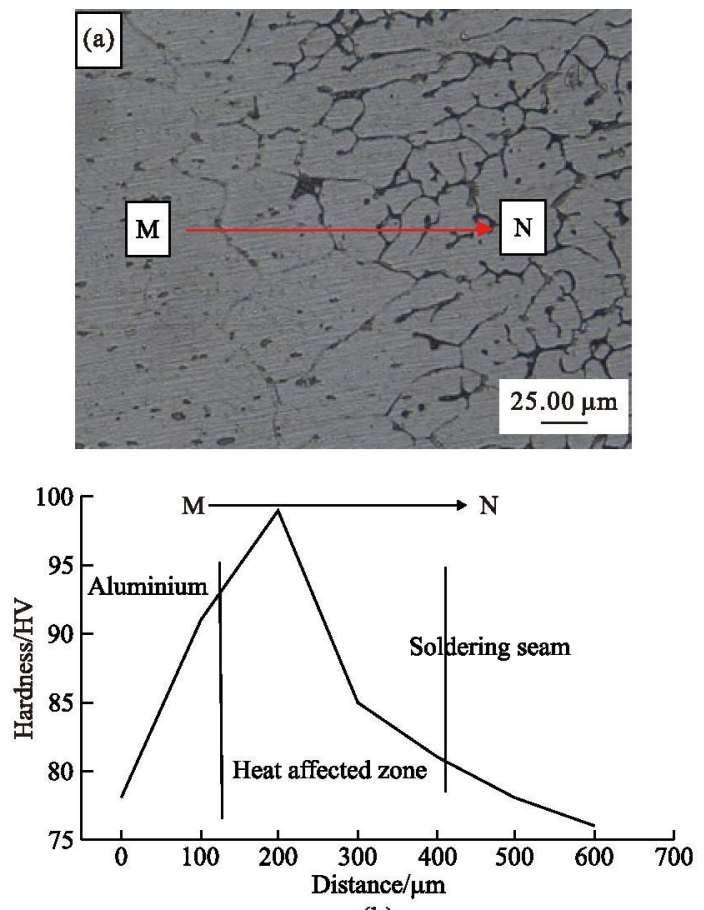

(b)

Fig. 17 Distribution of Vickers hardness of melting zone

Fig. 17 shows the distribution of Vickers hardness of melting zone. The microhardness of the HAZ was higher than that of the parent metal and brazing seam. At the HAZ, the crystal grains grew abnormally due to the influence of the welding arc heat. Although the heat input could lead to coarse grain crystal growth, due to the larger cooling rate, there was a large temperature gradient. The grain had already crystallized when the grain was still not grown too big, formed a small granular crystal, and it could ensure the joint quality.

3.2.2 The strengthening coupling mechanism of brazing seam interface

The grain grew in a whisker shape at the brazing interface. Some of them were crushed by the arc force to form short rod-shaped $\mathrm{FeAl}_{3}$ and the rest are still growing at the interface. In the Al-based solder brazing seam the $\mathrm{FeAl}_{3}$ was star-shaped. And the EDS analysis results can be seen in Fig.18. The presence of strengthening phases in the brazing seam could be demonstrated. The whisker top was fragmented under the action of the arc force, and formed a short rodshaped $\mathrm{FeAl}_{3}$. On the other hand, at high temperature of the arc, the solid-liquid interface dissolved rapidly, and the precipitate underwent eutectic transformation in the liquid to form $\mathrm{FeAl}_{3}$. $\mathrm{FeAl}_{3}$ grew to form spherical and star-shaped aggregates into petal-like intermetallic.

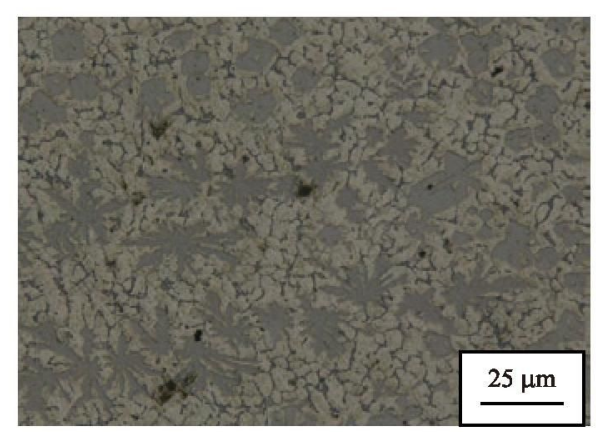

(a) Stellar $\mathrm{FeAl}_{3}$ morphology

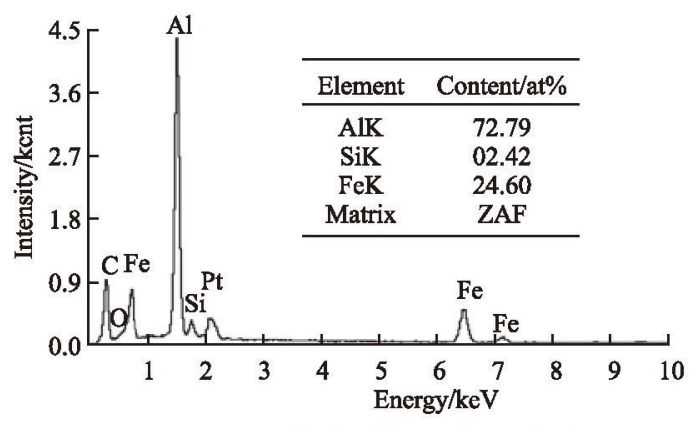

(b) Star-like EDAX analysis

Fig. $18 \mathrm{FeAl}_{3}$ morphology and EDAX analyses

\subsubsection{The mechanical properties of joint tensile}

With a small wire feeding speed, the crack cracked at the soldering feet, and expanded along the interface layer until the crack was formed. The tensile fracture schematic diagram can be seen in Fig.19.

The tensile fracture schematic diagram can be seen in Fig.20. With a large wire feeding speed, the 
cracks mainly appeared in the heat affected zone of the aluminum alloy. The tensile shear strength of the sample can be seen in Table 5 .

Table 5 Results of tensile test

\begin{tabular}{ccccc}
\hline Sample & $\begin{array}{c}\text { Wire feed } \\
\text { rate/(m/min) }\end{array}$ & $\begin{array}{c}\text { Welding } \\
\text { speed/(mm/min) }\end{array}$ & $\begin{array}{c}\text { Tensile } \\
\text { strength/ } \\
\text { MPa }\end{array}$ & $\begin{array}{c}\text { Fracture } \\
\text { location }\end{array}$ \\
\hline A1 & 3.9 & 250 & 104.1 & $\begin{array}{c}\text { Brazing seam } \\
\text { interface }\end{array}$ \\
A2 & 3.9 & 300 & 175.2 & Brazing seam \\
A3 & 3.9 & 350 & 120.3 & Aluminum HAZ \\
\hline
\end{tabular}

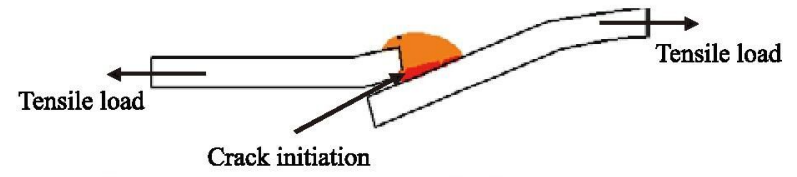

Fig. 19 The macroscopic tensile figure of sample 1

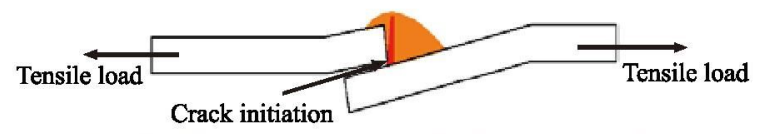

Fig.20 The macroscopic tensile figure of sample 3

Energy calculation formula:

$$
Q=I U / V
$$

where $I$ is welding current ; $U$ is welding voltage; $V$ is Welding speed.

When the energy of the welding line was small, the action of arc stirring was weak. Therefore the reaction in the interface was not strong and the connection with base metal was weak. It had a poor connection to base material, and the fracture happened at the interface. When the welding energy was larger, there was a larger are force to make the brazing seam particles increase. However, the grain grew quickly and increased its brittleness tendency.

\subsubsection{Fracture analysis of joints}

Fig. 21 shows the tensile fracture SEM morphology. The edge of the crack shows obvious grain boundary delineation, which shows the evident characteristic of intergranular brittle rupture. And it can be seen in Fig.21 (a). With the crack growth, in the middle part there are a small number of small pit, which is basic topography of dimple fracture. And it can be seen in Fig.21 (b). However, it can be ignored because it only accounts for a small part. At the same time, a large number of river-like features can be seen, called cleavage brittle facture.

With the crack growth, in the middle part, there was a small number of small pit, and a river pattern

appears, accompanied by pit, which could be judged as a ductile-brittle composite fracture.

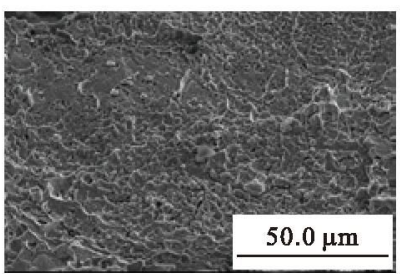

(a) Edge fracture appearance

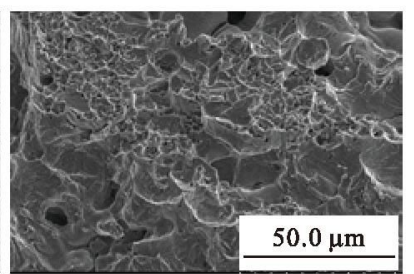

(b) Center fracture appearance Fig. 21 Fracture morphology of the samples

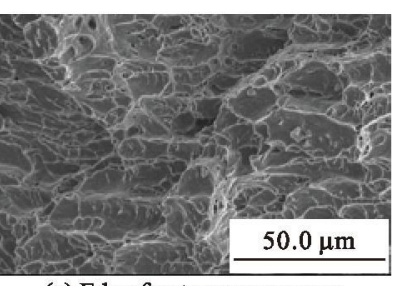

(a) Edge fracture appearance

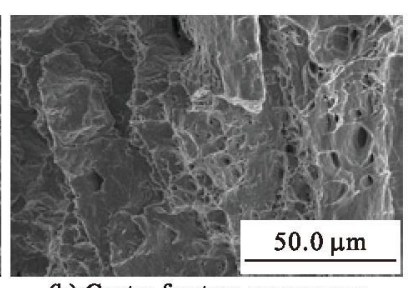

(b) Center fracture appearance
Fig.22 Fracture morphology of the samples

When the welding line energy is small, the arc stirring effect is weak, and the crystal grains growth are not sufficient. The weld is not significantly strengthened and does not provide conditions for the dissolution and diffusion reaction between the interface elements, resulting in a weaker bond strength interface. Therefore tensile specimens had brittle fracture at the weaker interface before being plastically deformed. When the arc current is large, the arc agitation becomes severe, and the grain fragmentation phase particles increase significantly. However, due to the larger heat input, the grain had a greater excessive growth, resulting in greater stress concentration. The brittleness tendencies of the joints had increased. Therefore, the fracture occurred at the brazing seam.

\section{Conclusions}

a) In the melting zone, it mainly contained $\alpha$-Al and Al-Si eutectic. Near the interface reaction layer of galvanized steel side, it was mainly $\mathrm{Fe}_{2} \mathrm{Al}_{5}$. On the side of the aluminum alloy base metal, the main structure was acicular $\mathrm{FeAl}_{3}$. $\mathrm{Al}_{8} \mathrm{Fe}_{2} \mathrm{Si}$ ternary alloy grew around the edge of $\mathrm{FeAl}_{3}$. Aluminum-zinc solid solution and aluminum-zinc eutectic mainly existed in the zinc-rich area.

b) The current size had no significant effect on the type and morphology of the compounds produced in the interface layer. The thickness of the interface layer had a large relationship with the size of the current. With a larger current, the hardness of the interface compounds 
increased and the brittleness tends to increase.

c) Through the tensile shear test on the joint, the crack mainly occurred in the heat affected zone of the base metal of aluminum alloy. And the highest tensile strength of the joint was 175.2 MPa.

d) The type and shape of the compound formed by the interface layer have no significant influence on the change of current size, but the change of thickness has a great relationship with it. When the current is large, the thickness of the grain growth reaction layer is increased, resulting in an increase in the hardness of the interface compound, which directly causes an increase in the brittleness tendency.

\section{References}

[1] Patterson E E, Hovanski Y, Field D P. Microstructural Characterization of Friction Stir Welded Aluminum-Steel Joints[J]. Metallurgical \& Materials Transactions A, 2016, 47(6): 2 815-2 829

[2] Taban E, Gould J E, Lippold J C. Dissimilar Friction Welding of 6061T6 Aluminum and Steel Properties and Microstructural Characterization[J]. Materials \& Design, 2010: 2 305-2 311

[3] Elrefaey A, Ross N G. Microstructure and Mechanical Properties of Cold Metal Transfer Welding Similar and Dissimilar Aluminum Alloys[J]. Acta Metallurgica Sinica (English Letters), 2015, 28(6): 715724

[4] Kovacscoskun T, Volgyi B, Sikarinagl I. Investigation of Aluminum-steel Joint Formed by Explosion Welding[J]. Journal of Physics: Conference Series, 2015, 602: 012026

[5] Zhang H T, Liu J K. Microstructure Characteristics and Mechanical Property of Aluminum Alloy/stainless Stecl Lap Joints Fabricated by MIG Welding-brazing Process[J]. Materials Science and Engineering A, 2011, 528: 6 179-6 185

[6] Zhang G F, Su W, Zhang J X, et al. Friction Stir Brazing: a Novel Process for Fabricating Al/Steel Layered Composite and For Dissimilar Joining of Al to Steel[J]. Metallurgical and Materials Transactions A, 2011, 42: $2850-2861$

[7] Kovacscoskun T, Volgyi B, Sikarinagl I. Investigation of Aluminum-steel Joint Formed by Explosion Welding[J]. Journal of Physics. Conference Series, 2015, 602:012026

[8] Gang Z, Chen M J, Yu S, et al. Analysis and Modeling of the Growth of Intermetallic Compounds in Aluminum-steel Joints[J]. Rsc Advances, 2017, 7(60): 37 797-37 805

[9] Dong H, Hu W, Duan Y, et al. Dissimilar Metal Joining of Aluminum Alloy to Galvanized Steel With Al-Si, Al-Cu, Al-Si-Cu and Zn-Al Filler Wires[J]. Journal of Materials Processing Technology, 2012, 212(2): 458-464

[10] Czechowski M. Stress Corrosion Cracking of Explosion Welded Steel-Aluminum Joints[J]. Materials \& Corrosion, 2015, 55(6): 464467

[11] Dong H, Yang L, Dong C, et al. Arc Joining of Aluminum Alloy to Stainless Steel with Flux-cored Zn-based Filler Metal[J]. Materials Science and Engineering A, 2010, 527(26): 7 151-7 154

[12] Dong H, Yang L, Dong C, et al. Improving Arc Joining of Al to Steel and Al to Stainless Stecl[J]. Materials Science and Engineering A, 2012, 534: 424-435
[13] Dong H, Liao C, Yang L, et al. Effects of Post-weld Heat Treatment on Dissimilar Metal Joint Between Aluminum Alloy and Stainless Steel[J]. Materials Science and Engineering A, 2012, 550: 423-428

[14] Zhu Z, Wan Z, Li Y. Microstructure and Mechanical Properties of Aluminum Alloy/stainless Steel Butt Joint Using Laser-MIG Hybrid Welding-brazing Method[J]. International Journal of Modern Physics $B, 2017,31(16-19): 1744035$

[15] D R, Achar J, Ruge S. Metallurgical and Mechanical Investigations of Aluminum-steel Fusion Welds[J]. Aluminum, 1980, 56(6): 391-397

[16] Ramachandran K K , Murugan N, Shashi K S. Friction Stir Welding of Aluminum Alloy AA5052 and HSLA Steel: Mechanical and Microstructural Characterization of Dissimilar Friction Stir Welded Butt Joints[J]. Welding Journal, 2015, 94(9): 291-300

[17] Song J L , Lin S B , Yang C L. Spreading Behavior and Microstructure Characteristics of Dissimilar Metals TIG Welding-brazing of Aluminum Alloy to Stainless Steel[J]. Materials Science and Engineering A, 2009, 509: 31-40

[18] Dong H G, Yang L Q, Dong C. Arc Joining of Aluminum Alloy to Stainless Steel With Flux-cored Zn-based Filler Metal[J]. Materials Science and Engineering A, 2010, 527: 7 151-7 154

[19] Chang Q, Sun D, Gu X. Microstructures and Mechanical Properties of Metal Inert-gas Arc Welded Joints of Aluminum Alloy and Ultrahigh Strength Steel Using Al-Mg and Al-Cu Fillers[J]. Journal of Materials Research, 2017, 32(3): 666-676

[20] Fereiduni E, Movahedi M, Kokabi A H. Aluminum/steel Joints Made by an Alternative Friction Stir Spot Welding Process[J]. Journal of Materials Processing Tech., 2015, 224: 1-10

[21] López E A T, Ramirez A J. Effect of Process Parameters in Obtaining Aluminium-steel Joints and Their Microstructure by Friction Stir Welding (FSW)[J]. Welding International, 2015, 29(9):689-697

[22] Naumov A, Mertin C, Korte F. On the Growth of Intermetallic Phases by Heat Treatment of Friction Stir Welded Aluminum Steel Joints[J]. Production Engineering, 2017, 11(2): 175-182

[23] Sridharan N, Wolcott P, Dapino M. Microstructure and Mechanical Property Characterisation of Aluminium-steel Joints Fabricated Using Ultrasonic Additive Manufacturing[J]. Science \& Technology of Welding \& Joining, 2016, 22(5): 1-8

[24] Sridharan N, Wolcott P, Dapino M. Microstructure and Mechanical Property Characterisation of Aluminium-steel Joints Fabricated Using Ultrasonic Additive Manufacturing[J]. Science \& Technology of Welding \& Joining, 2016, 22(5): 1-8

[25] Su Y, Hua X, Wu Y. Effect of Input Current Modes on Intermetallic Layer and Mechanical Property of Aluminum-steel Lap Joint Obtained by Gas Metal Arc Welding[J]. Materials Science \& Engineering A Structural Materials Properties Microstructure \& Processing, 2013, 578(31):340-345

[26] Yi Z, Li F, Guo G. Effects of Different Powders on the Micro-gap Laser Welding-brazing of an Aluminium-steel Butt Joint Using a Coaxial Feeding Method[J]. Materials \& Design, 201 6, 109: 10-18

[27] Yi Z, Guo G, Li F. The Interface Control of Butt Joints in Laser Braze Welding of Aluminium-steel With Coaxial Powder Feeding[J]. Journal of Materials Processing Technology, 2017, 246: 313-320

[28] Yu S, Jie L, Gang Z, et al. Corrosion Behavior of Aluminum-Steel Weld-Brazing Joint[J]. Journal of Materials Engineering \& Performance, 2016, 25(5): $1916-1923$ 